\title{
Research Needs on Western Rangelands
}

\author{
J. O. KLEMMEDSON, REX D. PIEPER, DON D. DWYER, \\ WALTER F. MUEGGLER, AND M. J. TRLICA
}

Highlight: A brief history of rangelands leading to the current status of range research in the western United States is reviewed. Five categories of new or unresolved problems needing research are identified. Ranked by priority, the five are: (1) dynamics of individual plants and plant communities; (2) identification, classification, and inventory of range ecosystems; (3) improvement of rangelands for increased productivity and stability; (4) short- and long-term grazing impacts; and (5) influence of economic, social, and political constraints on management of range resources. Recommendations are made for some redirection of current research and for organizing, administering, and coordinating research activities.

About $70 \%$ of the westem states consists of rangeland, where climate, soils, physiography, or economics restricts development for intensive agriculture. The characteristic vegetation is herbaceous or shrubby, often with a tree overstory. In the more moist portions of this region, rangeland overlaps with forest on 50 to 75 million acres, the exact acreage depending on criteria used to define forest. Here, competition for the various uses becomes intense and the value of forage for livestock is often secondary to other uses. Competing demands for land are fewer in more arid, nonforested portions of the region where weather is more variable, primary productivity lower and more erratic, and negative impacts from inappropriate land use more apparent. Since settlement by European man, nonforested rangelands have been valued most for livestock grazing-perhaps their highest economic use. Historically, improper grazing practices have caused public controversy on both forested and nonforested rangeland; and because of overgrazing, often combined with periods of drought, much deterioration of rangeland resources has resulted.

Significant improvement in range condition has been achieved since passage of the Taylor Grazing Act in 1934.

This paper has been adapted from a report of a Western Regional Task Force, RP 2.06, titled, "Range, Wildlife Habitat and Fisheries: Research Needs and Priorities." It is a contribution of the Regional and National Agricultural Research Planning System. Although organized under the Forest Resource Research Program Group, the Task Force feels its recommendations are broad and apply to all western rangelands.

The authors are the Task Force Chairman and members of the range sub-task force. They are professor, School of Renewable Natural Resources, University of Arizona, Tucson 85721; professor, Department of Animal and Range Sciences, New Mexico State University, Las Cruces 88003; professor and head, Department of Range Science, Utah State University, Logan 84322; principal range ecologist, Intermountain Forest and Range Experiment Station, Logan, Utah 84321; and associate professor, Department of Range Science, Colorado State University, Fort Collins 80521 .

The authors gratefully acknowledge the assistance of many colleagues who contributed with their ideas in discussions with the authors prior to convening the Task Force. Although this body of personal knowledge and current CRIS reports were important information sources to the range sub-task force, this paper represents the combined thinking of the authors and they accept full responsibility for its conclusions.

Manuscript received August 8, 1977.
Better range management, based on findings of range research and recognition of how multiple resources can be used more compatibly, has brought this about. The more moist, forested ranges have improved the most, but improvement on most rangelands has not achieved the expected stability and full productivity. The current rate of range improvement and the present status of range management do not reflect our current state of knowledge. Economic, social, and political constraints are often a deterrent to full application of what is presently known.

There are compelling reasons to use and care for western rangelands in a manner that insures their highest contribution to the public good. During the early 1960's, when increasing emphasis was placed on feedlot production of cattle and sheep, the contribution of the western range to livestock production diminished in importance in the eyes of agricultural policymakers. As a result, federal appropriations for the traditional areas in management and research on ranges have declined steadily over the past decade and a half. But the relative importance of range and pasture forages in livestock production increased sharply in 1972-1974 with worldwide food shortages and high prices of grain. This trend can be expected to continue; it would not be prudent to view the abundance of grain we have experienced in 1977 as more than a temporary pause in the continuing worldwide food crisis. Thus, the demand for U.S. grain in the international market and the importance of grain as foreign exchange to balance payments for needed imports of oil and other scarce items will grow. As a result, the price of grain will increase to levels where it is less feasible economically to finish livestock on high grain rations to the extent practiced in the past. It is now becoming more economical to substitute roughages for feed grains. Additionally, the present grading system of meat does not encourage feeding cattle to a high finish.

Rangelands always have been important for breeding herds that produce feeder lambs and calves for fattening and finishing on high grain rations. But with a higher cost of grain and the willingness of consumers to purchase meat with less finish in favor of lower prices, the demand for pasture and range forage will increase. In turn, this trend should enhance the value of western rangeland for the production of red meat. However, funding for traditional areas of management and research on rangeland has not caught up with the increasing demands for range resources.

Simultaneously, pressure by nonconsumptive users and formerly nontraditional users of forests and rangelands have been 
increasing. Environmentalists and various recreationist groups are showing more concern for rangelands and are demanding better management and a voice in the decision-making process governing land use. The strength of these groups is manifested by the impact of recent court decisions favoring the plaintiffs. Examples are lawsuits of the Natural Resources Defense Council vs BLM contesting management of grazing lands and the Isaac Walton League vs Butz over timber harvesting practices on the National Forest System.

The situation is clear. Research and management of western rangelands have been inadequate and lacking in balance for too long; moreover, many resource values have been neglected in past research efforts. Thus, we find ourselves doing too much piecemeal management or management for one or a few traditional uses and essentially no management for other range resources. We also lack adequate data to deal with the current issue of the impact of range use on environmental values. There is a clear mandate for immediate solutions to these longstanding problems. But the proper solutions will come only with concerted and aggressive action by professionals trained in the sciences of natural resource management backed by vigorous and progressive research programs. Otherwise, the range will be managed by default and as dictated by emotion, politics, and irrelevant issues.

\section{Criteria for Identifying Research Needs and Priorities}

The primary mission for this sub-task force was to identify new and unresolved problems of rangelands. We comment only briefly on active research programs. Failure to enforce the strong aspects of current range research should not be interpreted as criticism of current research direction.

Our selection of range problems currently in need of research and the priorities of allocating research resources to the solution of these problems was based on the following criteria. Each criterion was given approximately equal weight in assignment of priorities.

\section{Social Demands and Political Constraints}

Much has happened in the past two decades, both nationally and internationally, to alter the needs and demands of society for the resources of western rangelands. The world demand for food and a diminishing amount of cropland in the United States have caused an increase in the importance of rangelands for production of red meat. The priority of land uses is changing. Citizen groups are vigorously expressing their concerns over land management and are now an important force in the decisionmaking process. New political constraints in response to changes in land-use and environmental concerns now make it necessary to evaluate the impact of management decisions on a variety of on- and off-site resources.

\section{Present State of Knowledge}

In this evaluation we have stressed research needs not adequately covered by existing research programs. If information needed for solution of a problem is already available, or is currently being sought by a substantial research effort, that problem was deleted or given low priority for initiation of new research. Task Force members feel many management problems remain unsolved for which there exists the basic knowledge necessary for solutions.

\section{Probability of Success}

Despite the substantial benefits that might result from solution of a particular resource problem, achievement of these benefits is unlikely if the probability for solution of the problem is poor. Research on some complex problems is not feasible because of obvious constraints on funding, scientific talent, or lack of suitable technology and methodology.

\section{Likelihood of Extensive and Immediate Use of Results}

Sufficient funds are never available to work on all problems needing research. Therefore, it is important to focus attention on research essential for the solution of major problems. But it is even more important that unresolvable constraints do not prevent application and extensive use of the new research findings once they are available.

\section{Logical Sequence of Scientific Inquiry}

The solution to many research problems logically will be found by a sequential pattern of research. In the selection of problems needing research, it is important to consider the orderly acquisition of information.

\section{Research Needs}

In our evaluation of new research needs on western rangelands, we have delineated five broad problem categories. We consider these the most pressing current problem areas. Each major problem is briefly described, the general research objectives related to the problem outlined, and approaches to problem solutions suggested.

\section{Problem Category I: Identification, Classification, and Inventory Range Ecosystems}

No system of range identification and classification is currently applicable and consistent over broad areas of the range region. Systems currently in use vary among geographic regions and agencies responsible for the lands. Some systems are based on an identification of both site potential and range condition, while others neglect an evaluation of site potential altogether. The resulting array of systems seriously restricts the usefulness and application of knowledge acquired through research and experience. Land managers need information on range condition in relation to capability of sites to produce forage and sustain various uses. An identification and classification system with regional or national acceptance and application is urgently needed. This would provide a common base upon which to inventory range sites, to evaluate range condition, to accumulate and build management experience, to assess environmental impacts, to extrapolate research results, and to plan management and improvements.

A uniform system for identification and classification of rangeland would provide a framework for all future research and management; it would be useful to land-use planners, managers, and researchers. The system should provide improved information for better allocation of resources among various users.

\section{Objectives:}

(1) Develop a uniform regional or national system for evaluating and classifying site potential, condition, and trend of range sites.

(2) Determine capabilities of classification units to support alternative land uses.

(3) Use output of (1) and (2) to allocate and integrate resource use and values for social needs.

(4) Determine the functional relationship between site potential and environmental factors. 
Any applicable research approach should be pursued, including those successfully used in development of habitat-type classifications, the system for identification and classification of soils in the United States, and the soil-vegetation survey of California. Identification and classification of site potential presumably should be based on an integration of data for vegetation, soil, climate, geology, landform, topography, and other resources combined to yield a distinctive unit for each range site.

\section{Problem Category II: Dynamics of Individual Plants and Plant Communities}

Rangeland ecosystems are extremely complex, exist over a broad range of environments, and are usually characterized by severe stresses. Physical stresses such as extremes of temperature, precipitation, soil moisture and nutrients, and biological stresses such as competition, disease, and herbivory all limit productivity. Moreover, ecosystems become vulnerable during periods of stress. Deterioration often ensues if stress conditions are not alleviated or allowed for through adjustments in management. Relatively little is known about ecosystem response to stress conditions and the mechanisms that produce ecosystem change. We often do not know how individual species respond to various stresses, especially grazing; hence, we are unable to explain community dynamics related to stress. Knowledge of basic physiologic and morphologic mechanisms of species causing changes in ecosystems is usually lacking. Managers need this knowledge to predict changes in plant communities and to devise prescriptions geared to specific stress conditions.

Objectives:

(1) Describe and explain mechanisms of interactions among plants, animals, soils, climate, and other environmental factors which lead to ecosystem changes.

(2) Determine requirements for key plant species and evaluate responses of individual plant species and communities to physical and biological factors contributing to stress.

Studies should be undertaken under both natural and controlled conditions; and they should be directed toward analysis of interactions affecting changes in plant species and communities. Answers to questions regarding basic mechanisms of ecosystem productivity and stability should be sought. Researchers should not overlook opportunities to adapt techniques and methodologies of other disciplies.

\section{Problem Category III: Improvement of Rangelands for Increased Productivity and Stability}

Rangeland improvement practices developed in the past have emphasized response in forage production. Virtually no attention has been given to the effect of range improvements on resources other than forage. Little is known about the long-term effects of range manipulations on water quality, wildlife, and fish habitat, soil stability, and other resource values. By concentrating on short-term objectives in the past, we often achieved only temporary gains in forage production. There are few examples of long-term monitoring of plant community responses to specific vegetation manipulation practices. Failure to achieve and maintain stability in vegetation and soils following improvements has resulted from lack of understanding of ccosystem processes. We are unable to prescribe integrated management systems to fit conditions of the post-improvement system. Many examples of range improvement can be characterized as "piece-meal" efforts; they usually lack the necessary adjustment in grazing management practices to provide for maintenance of the altered ecosystems. The results have often been temporary gains with slow reversion to the preimprovement condition.

This research is important for many reasons. Many western ranges are producing far below their inherent capability and are not contributing to their potential for satisfying human needs. We need to restore rangelands to resemble more nearly their potential ecological condition and thus achieve greater stability of all range resources. Restored ecological productivity will enhance most resource values, regardless of kind, and contribute greatly to red meat production with a low expenditure of fossil fuels.

\section{Objectives:}

(1) Evaluate impacts of range manipulation practices on major ecosystem components (i.e., producers, consumers, and decomposers and the abiotic environment).

(2) Develop integrated systems of management designed to maintain productivity and stability following manipulation.

(3) Improve plant materials for various resource needs.

(4) Develop improved methods for on-site water management.

(5) Develop potential sources of biological $\mathrm{N}$-fixation and develop management techniques to utilize them.

We believe emphasis should be placed on using present knowledge of range improvement methods to develop integrated systems of range improvement. This should include the design of management prescriptions tailored to ecosystems improved by various manipulation practices. Consideration should be given to all ecosystem components (not just the forage resource) and the changes in components caused by manipulation. Ideally, in the development of integrated systems of improvement and management, consideration would be given to all applicable means of accommodating animal reductions caused by the nonuse or restricted use that may be required on the improved areas. This would provide incentive for improvement. In this regard, new research into development of supplements and nontraditional sources of livestock feeds (such as waste products for use in combination with range forage) is encouraged. Presumably, the team approach could be effectively used to solve these research problems.

\section{Problem Category IV: Short-and Long-Term Grazing Impacts}

Grazing studies of the past have been stereotyped, largely oriented to single goals, and were evaluated primarily in terms of vegetational and livestock responses. The effects of grazing treatments on soil factors also have been measured to a limited extent. The scope of future grazing studies should be expanded to include impacts on other rangeland resources including wildlife. The Natural Resources Defense Council vs BLM law suit focused attention on grazing impacts on federal lands and serves to illustrate the paucity of data concerning the influence of grazing on resources other than vegetation and livestock.

Land managers must be in a position to predict the impact of grazing management decision on all components of forest and range ecosystems. We also must be able to differentiate among grazing stress and other physical and biological stresses in terms of their effects and interactions. In the past, it has been too easy to blame livestock grazing for range damage that in fact may have been caused partly or entirely by other stresses. 


\section{Objectives:}

(1) Determine impacts of grazing management systems on recreation, wildlife, fisheries, nonpoint source pollution, and other watershed values as well as on livestock, individual plants, and plant communities.

Grazing studies usually require a great investment of facilities, personnel, and time, yet rather limited and unsatisfactory results often have been obtained in the past. Therefore, new grazing studies should be started only with considerable caution, firm commitments for long-term funding, and after very intensive planning. Grazing studies already underway should be examined for opportunities to include the objective delineated above. The studies should be based on growth requirements of key plants and include adequate replication. Researchers should seek imaginative and innovative alternatives to the traditional approach to grazing studies. One possible approach would be to combine grazing studies and demonstration projects which involve whole systems of management rather than the traditional single-goal grazing studies. Federal grazing allotments might be managed to collect data for this specific research objective and under an incentive system to achieve cooperation from permittees. Other approaches involving private livestock operators should be explored.

\section{Problem Category V: Influences of Economic, Social, and Political Constraints on Management of Range Resources}

The history of the American range, particularly those portions now administered by the federal government, discloses a sequence of events under which condition and stability of ranges have changed dramatically over time. Most of these lands have suffered from misuses. Although they have recovered to some extent, in most cases, they are still less productive and less stable than they once were. Land managers tend to point to so-called "overgrazing," often coupled with other physical and biological stresses, as the direct cause of destructive change. However, misuse or poor management can often be attributed indirectly to economic, social, and political pressures. The pressures which prevailed during the period of deterioration are in many instances still a factor in slow rates of range recover; they only differ in kind and magnitude. Restrictive and perhaps out-of-date policies seriously hamper our ability to put into practice range management knowledge already available. Laws and policies governing tenure status of grazing permits, grazing fee schedules and distribution of receipts from grazing on federal land, predator management, and many others seemingly have great influence on the incentive to invest on a short- or long-term basis in range management. The mood of federal agencies, the Administration, and Congress regarding the low priority of range resources for appropriations has seriously impaired improvement over the past 25 years, but especially in the last decade. Now, new forces, especially environmentalist groups and the courts, are influencing decisions regarding resource management. Researchers should examine the influence that these various forces have on range management both in the private and public sectors, and determine what changes should be made. Policymakers need to understand better the impact of their decisions which influence the rangeland user, consumer, and society at large.

\section{Objectives:}

(1) Determine the influence of government policies and legal, social, and economic constraints on the current and future status of range resources.
This research will involve unique combinations of talent. We visualize that individuals with backgrounds in range science, economics, political science, sociology, and law will need to collaborate in team efforts. The research may involve the analysis of data collected from case studies, development of models, and testing of alternative solutions.

\section{Research Priorities}

We partitioned problems identified above by two measures of priority: (1) a percentage priority, which suggests the relative distribution of research resources to the various problems, and (2) a ranking, which portrays the relative importance of each problem for research. and Inventory of Range Ecosystems

II. Dynamics of Individual Plants and Plant Communities

III. Improvement of Rangelands for Increased Productivity

IV. Short- and Long-Term Grazing Impacts

V. Influence of Economic, Social, and Political Constraints on Management of Range Resources

We believe the research problems ranked 1 and 2 above need immediate attention.

\section{Evaluation of Current Research}

We believe some lines of current research require redirection. For example, research on mechanical and herbicidal control of noxious plants has produced some effective methods, but new knowledge is still needed. Thus, some of this research should be continued to assure that methodology keeps pace with technology. However, unless additional funds can be obtained, we feel a large portion of noxious plant control research should be reoriented into learning how present methods of control can be utilized more effectively and integrated into systems of range improvement for specific problems. We favor expanding research on biological control of noxious plants. We also believe that research on plant control by use of fire should be continued.

Research on dates and rates of fertilizer application and on large empirical grazing system and grazing intensity studies should be greatly reduced or restructured; present knowledge in this area exceeds current application. Research on remote sensing of rangelands should be examined critically for usefulness of results obtained to date and those expected in the future. We also recommend abandonment of modelling research for academic purposes per se; goal-oriented modelling research has been productive and should be continued.

\section{Recommendations for Organizing, Administering, and Coordinating Research Activities}

Solutions to research problems are coming too slowly and are not meeting the need of resource managers. The difficulty, in part, lies in poor information transfer, failures in research planning and administration, and funding which is inadequate to cope with research needs. The downward trend over the past 10 
years in funding for research and management of rangelands reflects the failure of government policymakers to recognize and understand the importance of rangelands. They fail to grasp the significance of the current and potential role of rangelands in red meat production, and that the western range is a region rich in many other resource values that must be maintained in the national interest. Western rangelands that have not regained an acceptable state of condition since earlier periods of misuse are susceptible to erosion and flooding. The damages incurred on-site, to adjacent dependent communities, and to downstream areas including municipalities are insidious and costly, but frequently overlooked. In the absence of adequate research and proper management, these damages will mount and resource values will decline. Policymakers need to recognize these social costs of failing to manage rangelands properly, and that these alone are justifiable reasons for maintaining a strong research and management program for western rangelands.

Even in the absence of new funds for research, some progress can be achieved by better utilization of current funds. In this regard, stringent peer review procedures must be employed when assessing research projects for initiation or continuation. Objectives for some currently funded projects appear too broad; they should be sufficiently narrow to reasonably assure accomplishment within the stated duration of the project. However, shortsighted emphasis on objectives that are too narrow often leads to disorderly and fragmented research efforts. This is particularly detrimental to the comprehensive approach often required for ecosystem research involving multiple and interdependent resource values. In such cases, specific short-term objectives must be logically structured into long-term projects which may be required for problem solution.

Long-term projects should not be discouraged; the nature of some problems makes them mandatory. Rather, they should be funded on a short-term basis (maximum of 5 years) but with provision for continuation if adequate progress is demonstrated. Unproductive projects should be promptly abandoned and funds reallocated. Rapid shifts in priorities for research from year to year to fit what is currently in vogue in terms of granting agencies rather than addressing the real research needs are upsetting to productive research efforts and should be discouraged. Flexibility in research programming may be prudent on a small scale to accommodate critical emerging problems. and to help maintain research budgets. However, rapid shifts are wholly unrealistic in terms of satisfying research needs, maintaining continuity in a research program, and solving resource management problems.

Successful planning and coordination of range research requires up-to-date information on research activities nationwide. The Current Research Information System (CRIS) was developed in 1966 to meet this need for agriculture and related sciences. CRIS is apparently not serving as a good clearinghouse for research in range management. We rated CRIS reports as poor in providing information on existing research projects, and the progress of research. Procedures for completing CRIS reports are often out-of-date, research objectives are stated too broadly, and reported progress is too incomplete to be useful.

In planning range research it is imperative that we remain continually aware of the many values inherent in rangelands. Forage is not the only product; rangelands also produce wildlife, water, recreational opportunities, minerals, sources of energy, and often wood fiber. All of these values are becoming increasingly important and more frequently in demand by society. Management aimed at one value will inevitably affect the other values. Research must be directed towards unravelling these interrelations and providing the basis for sound multipleuse management of rangelands.

\section{Election Results}

The 1,877 ballots cast in the 1977 election were counted on December 2 . Selected by the membership to serve the Society during the next 3 years were:

\section{President Elect .... Daniel L. Merkel \\ Directors ........ Charles M. Jarecki \\ William Laycock}

The new officers will be installed at the forthcoming Annual Meeting in San Antonio, at which time Bob Williamson, the current president elect, will succeed to the presidency. Daniel Merkel will serve as president in 1979, and the two newly elected directors will serve for the 3-year term 1978-1980.

Retiring next month from the Board of Directors are Past President Bob J. Ragsdale and Directors Lyman G. Linger and E. H. Mcllvain. The very significant service rendered to the Society by these men is greatly appreciated.

Daniel Merkel is at present SCS range conservationist at the Rocky Mountain Forest and Range Experiment Station.

Charles Jarecki is a cattle and grain rancher in Polson, Mont. , and William Laycock is range scientist with the Agricultural Research Service.

A committee of members of the Colorado Section counted the ballots. Ballots and tally sheets are kept on file in the Society office for 1 year. 